\title{
O DISCURSO MUSICAL DO SÉCULO XVIII: EMULAÇÕES RETÓRICAS NA OBRA DE FRANCESCO GEMINIANI (1687-1762)
}

\author{
Marcus Held \\ Universidade de São Paulo - SP \\ Email:mvheld@usp.br
}

\section{Resumo:}

$\mathrm{Na}$ literatura dos séculos XVII e XVIII, centenas de tratados dedicados à composição, interpretação, ensino e reflexão musicais foram publicados e difundidos por todo o continente Europeu. Tais obras, que variam enormemente em relação à metodologia abordada por seus autores, costumam, frequentemente, trazer consigo a noção de que a música é análoga ao discurso verbal, ambos guiados pelas regras da retórica, e que sua finalidade seja ensinar, deleitar e mover o ouvinte. No caso de Francesco Geminiani (1687-1762), esta mesma ideia pode ser lida em sua obra tratadística. Neste artigo, pretende-se discorrer sobre diversas emulaçóes retóricas almejadas por Geminiani (1687-1762) em sua obra tratadística, sobretudo nas Regras para tocar com verdadeiro gosto (c.1748), Tratado sobre o bom gosto na arte da música (1749) e $A$ arte de tocar violino (1751). Nesses tratados, o autor não apenas alinhou-se às correntes de pensamento de sua época, representadas por Batteux, Hume e Montesquieu - na filosofia - e por Quantz, C. P. E. Bach e L. Mozart - na música -, mas também recuperou acepçóes do discurso falado, escrito e proferido, presentes nas retóricas clássicas De Oratore, de Cícero, e Institutio Oratoria, de Quintiliano. Observaremos que, no tocante à discussão filosófico-musical setecentista em torno da tópica do Gosto - lugar-comum no conjunto total de sua tratadística -, Geminiani apoia-se na recuperação e no debate de diversos preceitos sobre imaginação, juízo, decoro, ornamentação, performance e recepção, abordados pelos autores mencionados, tornando, assim, evidente sua visão da composição musical espelhada no discurso retórico. 
Palavras-chave: Francesco Geminiani. Retórica Musical. Gosto. Afetos.

\section{The eighteenth century musical discourse: Rhetorical emulations in the oeuvre of Francesco Geminiani (1687- 1762)}

Abstract:

In the literature of seventeenth and eighteenth centuries, hundreds of treatises on musical composition, performance, pedagogy and speculation were published and widespread throughout European continent. Those works, which vary enormously in regard to the methodology used by their authors, often use to bring the notion of music as analogue to the verbal speech, both guided by the rules of rhetoric, which its aim is to instruct, delight and move its listener. In the case of Francesco Geminiani (1687-1762), the same idea can be read in his treatises, mainly in Rules for playing in a true taste (c. 1748), A treatise of good taste in the art of musick (1749) and The art of playing on the violin (1751). In those works, the author has not only got himself connected to the currents of thought of his time, represented by Batteux, Hume and Montesquieu - in philosophy - and by Quantz, C. P. E. Bach and L. Mozart - in music -, but also recovered meanings of oral, written and delivered speech, present amongst the classics $D e$ Oratore, by Cicero, and Institutio Oratoria, by Quintilian. It will be observed that, in relation to eighteenth century philosophical and musical debates on Taste - commonplace in his treatises -, Geminiani is based on the recovery and the discussion of several precepts about imagination, judgement, decorum, ornamentation, performance and reception, approached by the above-mentioned authors. It is therefore evident his view of musical composition mirrored on rhetorical discourse.

Keywords: Francesco Geminiani. Musical Rhetoric. Taste. Affects. 
Na literatura dos séculos XVII e XVIII, centenas de tratados dedicados à composição, interpretação, ensino e reflexão musicais foram publicados e difundidos por todo o continente Europeu. Tais obras, que variam enormemente em relação à metodologia abordada por seus autores, costumam, frequentemente, trazer consigo a noção de que a música é análoga ao discurso verbal, ambos guiados pelas regras da retórica, e que sua finalidade seja ensinar, deleitar e mover o ouvinte (LUCAS, 2014, p. 72).

No caso de Francesco Geminiani (1687-1762), esta mesma ideia pode ser lida em sua obra tratadística. Nascido na Itália e discípulo de Arcangelo Corelli (1653-1713), Geminiani radicou-se em Londres em 1714, destacando-se, ainda em vida, como violinista virtuose, compositor e professor. Por ter em sua formação a presença de uma figura de tanto renome como a de Corelli, foi considerado no meio musical britânico como uma autoridade e, além disto, teve a possibilidade de trabalhar com os principais editores ingleses. A partir de 1748 , passou a dedicar-se à produção e à publicação de sua obra tratadística, somando, até o final de sua vida, sete volumes: Regras para tocar com verdadeiro gosto(c.1748), Tratado sobre o bom gosto na arte da música(1749), A arte de tocar violino(1751), Guida Armonica(1756/8), A arte do acompanhamento(1756/7), A Miscelânea harmônica (1758) e $A$ arte de tocar guitarra ou cistre(1760).

Neste artigo, pretende-se discorrer sobre diversas emulaçóes retóricas almejadas por Geminiani (1687-1762) em sua obra, sobretudo em seus três primeiros tratados. Neles, o autor não apenas alinhou-se às correntes de pensamento de sua época, representadas por Batteux, Hume e Montesquieu - na filosofia - e por Quantz, C. P. E. Bach e L. Mozart - na música -, mas também recuperou acepçóes do discurso falado, escrito e proferido, presentes nas retóricas clássicas De Oratore, de Cícero, e Institutio Oratoria, de Quintiliano. Observaremos que, no tocante à discussão filosófico-musical setecentista em torno da tópica do Gosto - lugar-comum no conjunto total de sua tratadística -, Geminiani apoia-se na recuperação e no debate de diversos preceitos sobre imaginação, juízo, decoro, ornamentação, performance e recepção, abordados pelos autores mencionados, tornando, assim, evidente sua visão da composição musical espelhada no discurso retórico. 
1. "Musical execution may be compared with the delivery of an orator. The orator and the musician have, at bottom, the same aim in regard to both the preparation and the final execution of their productions, namely to make themselves masters of the hearts of their listeners, to arouse or still their passions, and to transport them now to this sentiment, now to that" (trad. do original alemão E. Reilly).

2. "The Intention of Musick is not only to please the Ear, but to express Sentiments, strike the Imagination, affect the Mind, and command the Passions."

3. "Atque ego veliudiciopoteram esse contentus. Nam quis ignoratmusicen (ut de hac primum loquar) tantum iam illis antiquistemporibus non studii modo verumetiamvenerationishabuisse, ut iidemmusici et vales et sapientes iudicarentur (mittamalios) Orpheus et Linus; quórum utrumquedisgenitum, alterum vero, quia rudes quoqueatque agrestes ânimos admirationemulceret, non feras modo sedsaxaetiamsilvasqueduxisseposteritatismemoriaetraditum est. [...] Est etiam non inerudite ad declamandum ficta materia, in quaponiturtibicen, quisacrificanti Phrygiumcecinerat, actoillo in insaniam et per praecipitia delato accusari, quod causa mortis extiterit."

\section{RELAÇÕES ENTRE RETÓRICA E MÚSICA}

Uma obra de arte, segundo o pensamento setecentista, é dedicada a afetar seu receptor. Da mesma maneira que o principal objetivo de um orador, nos textos da retórica clássica, é excitar as emoçóes - ou os afetos - de seu ouvinte (CÍCERO, I v 17), $\mathrm{o}$ artistadeseja afetar seu público, despertando seus sentidos. Estudiosos da música do século XVIII podem testemunhar esta inteiração nas palavras de Johann Joachim Quantz:

A performance musical pode ser comparada à entrega do [discurso] de um orador. O orador e o músico possuem, no cerne, o mesmo objetivo tanto em relaçáo à preparaçáo quanto à execuçāo final de suas produçôes; isto é, [almejam] transformarem-se em mestres dos coraçóes de seus ouvintes, incitar ou roubar suas paixōes e transportá-los ora a este sentimento, ora àquele (2001 [1752], p. 119, trad. nossa ${ }^{1}$.

Da mesma maneira, Geminiani, um ano antes de Quantz, já havia mencionado, em $A$ arte de tocar violino, que "a intençâo da música é não apenas agradar aos ouvidos, mas também expressar sentimentos, atingir a imaginaçáo, afetar a mente e comandar as paixōes" (GEMINIANI, 1751, pref., trad. nossa) ${ }^{2}$. Paralelamente, em textos da retórica clássica, também é possível observar essa reflexão, uma vez que a música é capaz de mover seu receptor. Em Institutio Oratoria, Quintiliano comenta:

[...] A respeito da música, talvez eu pudesse estar satisfeito com a avaliaçấo dos antigos. Pois quem desconhece que a música, para falar dela em primeiro lugar, já então naqueles tempos antigos, foi objeto não apenas de paixão como também de veneraçáo, de modo que eram considerados músicos, poetas e sábios, como, omitirei outros, Orfeu e Lino: ambos de origem divina, mas conta-se que o primeiro, porque amansava até os seres primitivos e agrestes por ter deixado para a memória da posteridade o fato de arrastar não só as feras como também os rochedos e as florestas com o encantamento de sua música.[...] Há também um fato lendário, não rude para ser declamado, em que aparece um tocador de flauta, que havia tocado uma melodia frígia enquanto se fazia um sacrifício: devido a esse fato, o que sacrificava teve um acesso de loucura e se atirou num precipício; o tocador de flauta foi acusado de ter sido a causa da morte (I, X, 9, 32-33, trad, B. Bassetto) ${ }^{3}$. 
Ainda que o sentido de mover o receptor possa ter, na primeira parte dessa citação, um sentido praticamente literal, de arrastar feras, rochedos e florestas, percebe-se também que a música move a alma de seus ouvintes ao excitar sua variada gama de sentimentos e afetos. Esse pensamento foi retomado no Renascimento e permaneceu até o fim do século XVIII. $\mathrm{Na}$ obra de Geminiani, este quesito é abordado largamente. $\mathrm{Na}$ listagem dos catorze ornamentos contida em seu Tratado sobre o bom gosto na arte da música e reimpressa no tratado de violino acima mencionado, o autor providencia instruçóes de como executá-los e, em muitos casos, descreve a situação em que eles devem ser empregados, bem como o efeito de cada ornamento quando percebido pelo ouvinte. Listamos, a seguir, alguns casos em que isso ocorre:

(Segundo) Dotrinado com terminação: o trinado com terminação, sendo realizado de forma rápida e longa, é apropriado para expressar alegria. Todavia, se o realizarmos curto e mantivermos a extensão da nota contínua e suave, expressará, então, algumas das mais ternas paixóes.

(Décimo terceiro) Domordente: é apropriado para expressar diversas paixóes. Por exemplo, se realizado com força e continuamente longo, expressa fúria, raiva, determinaçáo etc. Se tocado menos forte e mais curto, expressa júbilo, satisfação etc. Entretanto, se o tocarmos muito suave e fizermos um crescendo, o mordente pode, então, denotar horror, medo, pesar, lamentação etc. Se tocado de forma curta e com um crescendo delicado, pode expressar afeição e deleite.

(Décimo quarto) Dovibrato: não pode ser descrito por meio de notas, como nos exemplos anteriores. Para realizá-lo, devemos pressionar o dedo fortemente sobre a corda do instrumento e mover o punho para dentro e para fora, lenta e igualmente. Quando uma nota longa com vibrato é acompanhada de um crescendo gradual, com o arco se movendo para perto do cavalete e de uma terminação muito forte, o vibrato pode expressar majestade e dignidade. Entretanto, realizado mais curto, com menos volume e mais suavemente, pode denotar afliçáo, medo etc.(GEMINIANI, 1749, p.3-4; trad. nossa) ${ }^{4}$.

Nesta leitura, percebe-se que a ornamentação é um grande recurso para comandar as paixões do receptor. Como é de se esperar, o autor recomenda que o emprego dos ornamentos seja realizado de modo diligente, isto é, com bom gosto:
4. "(Second,) Of the Turned Shake: The turn'd Shake being made quick and long is fit to express Gaiety; but if you make it short, and continue the Length of the Note plain and soft, it may then express some of more tender Passions. (Thirteenth) Of the Beat: This is proper to express several Passions; as for Example, if it be perform'd with Strength, and continued long, it expresses Fury, Anger, Resolution, \&c. If it be play'd less strong and shorter, it expresses Mirth, Satisfaction, \&c. But if you play it quite soft, and swell the Note, it may then denote Horror, Fear, Grief, Lamentation, \&c. By making it short and swelling the Note gently, it may express Affection and Pleasure. (Fourteenth) Of the Close Shake: This cannot possibly be described by Notes as in former Examples. To perform it, you must press the Finger strongly upon the String of the Instrument, and move the Wrist in and out slowly and equally, when it is long continued swelling the Sound by Degress, drawing the Bow nearer to the Bridge, and ending it very strong it may express Majesty, Dignity, \&c. But making it shorter, lower or softer, it may denote Affliction, Fear, \&c." 
5. "Thus I have collected and explain'd all the Ingredients of a good Taste, and nothing remains but to caution the Performer against concluding, that a mere mechanical Application of them, will answer the great Purpose of establishing a Character among the Judicious in all Arts ans Sciences, something must be left to the good Sense of the Professor; for as the Soul informs the Body, so every Rule and every Principle must be enforc'd by the Knowledge and Skill of him who puts it in Practice."

6. "Non enimsatisestdicerepresse tantum autsubtilierautaspere, non magisquamphonascoacutis tantum autmediisautgravibussonisauthorumetiamparticulisexcellere. Nam sicut cithara itaoratio perfecta non est, nisi ad imo ad summum omnibus intent nervisconsentiat."

7. "Il est un bon Goût. Cette proposition n'est point un problème: \&ceux qui doutent, ne sont point capablesd'atteindre aux uvesqu'ilsdemandent.

[...] Que de questionssouscetitre si connu, tant de foistraité, \& jamais afez clairementexpliqué."
Coletei e expliquei todos os ingredientes do bom gosto, e não resta nada a não ser alertar o intérprete a não concluir que uma mera aplicação mecânica deles levará ao grande propósito de estabelecer-se como um [músico de] caráter [judicioso] entre outros judiciosos em todas as Artes e Ciências. Algo deve ser deixado para o bom senso do professor, pois, assim como a alma afeta o corpo, toda regra e todo princípio devem ser feitos cumprir por meio do conhecimento e da habilidade daquele que os põe em prática(GEMINIANI, 1749, p. 4; trad. nossa) ${ }^{5}$.

Isto está de acordo, também, com os princípios de um discurso coerente da retórica clássica de Quintiliano:

Pois não é suficiente falar apenas com precisão, com sutileza ou com dureza, não mais que ao mestre de declamação não é o bastante destacar-se somente na emissão dos sons agudos, médios ou graves, como também de seus matizes intermediários. Realmente, como a cítara, também o discurso não é perfeito a não ser que, da mais baixa à mais alta corda, esteja bem afinado e coerente (II, VIII, 15, trad. B. Bassetto) ${ }^{6}$.

\section{GOSTO NA MÚSICA DO SÉCULO XVIII}

O conceito de gosto é amplo, de modo que uma discussão exaustiva sobre esse assunto excederia o escopo do presente artigo. No entanto, por ora, é conveniente discutir algumas ocorrências desse termo na literatura setecentista, para, assim, entender as supostas razóes pelas quais Geminiani teria publicado sua preceptiva.

O século XVIII testemunhou uma grande discussão acerca da ideia de gosto, assunto ao qual foram dedicadas diversas preceptivas. Charles Batteux (1713-1780) dedica-se a explicar o princípio que rege o fundamento de todas as belas-artes: a imitação. $\mathrm{O}$ gosto, nesse cenário, é fundamental para a imitação adequada da bela natureza. De acordo com o autor, era um assunto muito estudado: "existe um bom gosto. Essa proposiçáo não é um problema, e aqueles que duvidam disso não são capazes de conseguir as provas que requerem. [...] Quantas questóes sob esse título táo conhecido, tantas vezes tratado e nunca explicado de modo suficientemente claro!" (BATTEUX, 2009 [1746], p. 48, trad. N. Maruyama) ${ }^{7}$. Vemos, assim, que a discussão sobre os fundamentos do gosto era corrente, o que, por si só, já poderia justificar a publicação dessas obras de Geminiani.

Em todo caso, observa-se, dentre as diversas acepçóes do conceito aqui discutido, sua relaçáo com o julgamento e com o intelecto, 
termos que se relacionam com a faculdade do juízo. Isto é, o gosto se relaciona com a razáo no sentido de que permite diferenciar, qualificar e, finalmente, julgar:

Uma inteligência é portanto perfeita quando vê sem nuvens, e quando distingue sem erro o verdadeiro do falso, a probabilidade da evidência. Do mesmo modo, o gosto é perfeito quando, com uma impressão distinta, ele sente o bom e o mau, o excelente e o medíocre, sem nunca confundi-los e sem tomar um pelo outro. Posso então definir a inteligência: a facilidade de conhecer o verdadeiro e o falso, e de distingui-los um do outro. E o gosto: a facilidade de sentir o bom, o mau, o medíocre, e de distingui-los com certeza. Assim, o verdadeiro e bom, conhecimento e gosto, eis todos os nossos objetos e todas as nossas operações (BATTEUX, 2009 [1746], p. 49-50, trad N. Maruyama) ${ }^{8}$.

Desse modo, vê-se que o conceito de gosto está interligado com as questôes do discernir: diferenciar e qualificar. Se as definições básicas sobre gosto têm origem no sentido próprio do termo, isto é, a sensibilidade gustativa - vide Zedler: "Gosto, sabor (gustus, gout) é aquele, dentre os sentidos exteriores, que através de sua ferramenta própria, a língua, percebe o efeito específico das partículas salgadas dos corpos e o transmite à alma, pelo cérebro" (1708, p. 78; trad. nossa) ${ }^{9}-$, no âmbito das artes e, mais especificamente, em música, o termo estará relacionado, naturalmente, com a sensibilidade auditiva.

Ao observar as citaçóes de Batteux e de Zedler, percebe-se que o gosto trata, portanto, de uma questão ambivalente entre suas conotaçóes sensorial e racional. A primeira, tendo como subsídio a percepção pelos sentidos e, como fim, o efeito (sensação de prazer ou de repulsa); a segunda, a partir do discernimento, emite, então, um julgamento (bom ou ruim, agradável ou desagradável, belo ou feio). Ao final, elas se fundem, uma vez que só será possível julgar aquilo que tenha sido transmitido para o cérebro após a percepção pelos sentidos. Além disso, a predominância da razão é patente, visto que a percepção sensorial, por si só, é incerta (PAOLIELLO, 2011).

Apesar de citadas fontes setecentistas, visto que é o foco deste estudo, sabe-se que a relação entre gosto e razão tem origem na Renascença. Klein (1998, p. 333) direciona sua atenção para o termo giudizio[juízo], que, nessa época, "não era um ato de ordem puramente intelectual: pertencia a um domínio interme-
8. Une intelligence estdonc parfait, quandellevoit sans nuage, \&qu'elle distingue sans erreur le vraid'avec le saux, la robabilitéd'avecl'evidence. De même le Goûtest parfait aussi, quand, par une impression distincte, il sent le bon \& le mauvais, l'excellent\& le mediocre, sans jamais les consondre, ni les prendre l'un pour l'autre. Je puis doncdéfinirl'intelligence: lafacilité de connoîtrelevrai\&lefaux, \& de lesdistinguerl'un de l'autre. El leGoût: lafacilité de sentir lebon, lemauvais, lemédiocre, \& de lesdistingueraveccertitude. Ainsi, vrai\& bon, connoissance\&goût, voilà tousnos objects \&toutesnosoperations."

9. "Geschmack, Schmäcken (Gustus, Gout) istderjenigeunterdenenäusserlichenSinnen, welcherdurch sein eigen Werckzeug die Zunge, die besondereWürckung, so gewissesaurige von denenKörpernabgelöfeteTheiledarinnethun, empfindet, und durch das Gehirn der Seelemittheiset, welcheEmpfindung der Schmackgenennetwird." 
10. "It is universally allowed by the writers on optics, that the eye at all times sees an equal number of physical points, and that a man on the top of a mountain has no larger an image presented to his senses, than when he is cooped up in the narrowest court or chamber. It is only by experience that he infers the greatness of the object from some peculiar qualities of the image; and this inference of the judgment he confounds with sensation, as is common on other occasions. Now it is evident, that the inference of the judgment is here much more lively than what is usual in our common reasonings, and that a man has a more vivid conception of the vast extent of the ocean from the image he receives by the eye, when he stands on the top of the high promontory, than merely from hearing the roaring of the waters. He feels a more sensible pleasure from its magnificence; which is a proof of a more lively idea: And he confounds his judgment with sensation, which is another proof of it. But as the inference is equally certain and immediate in both cases, this superior vivacity of our conception in one case can proceed from nothing but this, that in drawing an inference from the sight, beside the customary conjunction, there is also a resemblance between the image and the object we infer; which strengthens the relation, and conveys the vivacity of the impression to the related idea with an easier and more natural movement." diário entre o intelecto e os sentidos”. O juízo, pois, é a reação ao percebido sensorialmente, como testemunhado em Zedler. Klein sustenta, ainda, que, até o surgimento do termo conhecido como "gosto", a relação entre sensação e razão era realizada pela faculdade do juízo. Nesse sentido, tem-se que, além de o gosto não pertencer apenas à ordem dos sentidos, o juízo não se relacionava apenas com a razão (PAOLIELLO, 2011). Dessa maneira, se juízo é uma "reação racionalizável imediata ao percebido" (KLEIN, 1998, p. 333), observa-se a relação intrínseca entre gosto e juízo, visto que, após a percepção sensorial, o discernimento perante o percebido é explicitado em forma de julgamento, como o bom ou o ruim. Como exemplo, a relação entre sentido, gosto e juízo pode ser evidenciada no raciocínio traçado por David Hume (1711-1776) - filósofo britânico do qual Geminiani, possivelmente, foi leitor (WILLIAMS, 2013, p. 13). No Tratado da natureza humana, Hume Hume elabora:

Todos os tratados de óptica admitem que o olho vê sempre o mesmo número de pontos físicos, e que a imagem que se apresenta aos sentidos de um homem quando este se encontra no topo de uma montanha não é maior que quando ele está confinado no mais estreito pátio ou aposento. É somente pela experiência que ele infere a grandeza do objeto, com base em certas qualidades peculiares da imagem; e isso, que é uma inferência do juízo, ele confunde com uma sensação, como costuma correr em outras ocasiōes. Ora, é evidente que, neste caso, a inferência do juízo é muito mais vívida que aquela que é comum em nossos raciocínios correntes. Um homem forma uma concepção mais vívida da vasta extensão do oceano pela imagem que recebe do olho, quando está no alto de um promontório, do que simplesmente pelo barulho das ondas. Extrai um prazer mais sensível de sua grandeza, o que prova uma presença de uma ideia mais vívida; e confunde seu juízo com uma sensação, o que é mais uma prova disso. Como a inferência é igualmente certa e imediata em ambos os casos, porém, essa vividez superior de nossa concepção em um caso só pode proceder do fato de que, ao fazermos uma inferência baseados na visão, existe, além da conjunção habitual, uma semelhança entre a imagem e o objeto inferido - e essa semelhança fortalece a relação transmitindo a vividez da impressão para a ideia relacionada com um movimento mais fácil e natural (2009 [1739-40], p. 142-143, trad.D. Danowski, grifos nossos) $)^{10}$. 
Outro importante preceptista do século XVIII, Montesquieu (1689-1755), afirma, sobre a relação entre o gosto e o intelecto, ou o "pensar", que:

A alma, independentemente dos prazeres que extrai dos sentidos, experimenta outros que lhe são próprios, como os que lhe despertam a curiosidade, os que lhe dão uma idéia de sua grandeza, de suas perfeiçóes, de sua existência como algo oposto ao sentimento da noite, o prazer de abarcar todo o conteúdo de uma idéia geral, o de ver um grande número de coisas etc., o de comparar, associar e separar idéias. Esses prazeres são inerentes à natureza da alma, independentemente dos sentidos, porque pertencem a todo ser que pensa (MONTESQUIEU, 2009 [1753], p. 13, trad. T. Coelho) ${ }^{11}$.

Nesse sentido, o filósofo afirma que "são os diferentes prazeres da alma que formam os objetos do gosto, tais como o belo, o bom, o agradável, o ingênuo, o delicado, o terno, o gracioso, o não sei o quê, o nobre, o grandioso, o sublime, o majestoso etc.” (MONTESQUIEU, 2009 [1753], p. 11, trad. T. Coelho) ${ }^{12}$. Esses prazeres, quando excitados, provocam no receptor o estado de deleite.

Dentre diversos autores que estudaram e descreveram o conceito de deleite, iremos nos concentrar na obra quinhentista de Cesare Ripa: Iconologia overo Descrittione dell'Imagini Universali, de 1593 e editado em Londres com o título Iconology, or Moral Emblems ("Iconologia, ou emblemas morais") em 1709, poucos anos antes de Geminiani se radicar naquela cidade. Nessa obra, o autor dedica-se a representar iconograficamente diversas faculdades da alma, assim como seus variados prazeres e paixôes. Pode-se, inclusive, recorrer ao tratado como a um dicionário, pois as representaçóes estão listadas no início da obra, bem como descritas textualmente. O emblema do conceito de deleite tem como suporte textual:

Um garoto de dezesseis anos com aspecto agradável; sua capa adornada com várias cores; uma guirlanda de rosas; um violino e seu arco; uma espada; um livro de Aristóteles e um de música; dois pombos a se beijar. Seu semblante denota deleite; o verde significa a vivacidade e a deleitabilidade dos prados verdes para a visão; o violino, deleite na audição; o livro, deleite na filosofia; os pombos, deleite amoroso (RIPA, 1709, p.23; trad. e grifos nossos) ${ }^{13}$.
11. "L'âme, indépendamment des plaisirs qui luiviennent des sens, en a qu'elleaur aitindépendammentd'e ux, et qui luisontpropres ; telssontceux que luidonnent la curiosité, les idées de sa grandeur, de ses perfections, l'idée de son existence opposée au sentiment du néant, le plaisird'embrasser tout d'une idée générale, celui de voir un grand nombre de choses, etc., celui de comparer, de joindre et de séparer les idées. Ces plaisirs sont dans la nature de l'âmeindépendamment des sens,

parcequ'ilsappartiennent à tout être qui pense."

12. "Ce sontcesdifférens plaisirs de notreâme qui forment les objets du goût, comme le beau, le bon, l'agréable, le naif, le délicat, le tendre, le gracieux, le je ne sais quoi, le noble, le grand, le sublime, le majestueux, etc."

13. "A Boy of sixteen, with a pleasant Aspect, his green Suit adorn'd with various Colours; a Garland of Roses; a Violin, and its Bow; a Sword; a Book of Aristotle, and one of Musick. Two Pigeons a-kissing. His Countenance denotes Delight. The Green signifies the Vivacity and Delightfulness of green Meadows to the Sight: the Violin, Delight in Hearing; the Book, Delight in Philosophy; the Doves, amorous Delight." 
14. "Le goût acquis affecte, change, augmente et diminue le goût naturel, comme le goût naturel affecte, change, augmente et diminue le goût acquis."
Desse modo, além de notarmos a ambivalência sensorial-racional nessa citação de Ripa, pode-se supor que o gosto seja o principal elo, nas artes, entre o efeito causado no receptor e o juízo a ser realizado após este primeiro estágio. Logo, o gosto é elemento primordial na formação do artista, pois é por meio dele que sua obra será apreciada e julgada.

No entanto, entra-se, com isso, em outra grande discussão setecentista: aquela que questiona se o gosto é algo naturalmente presente no artista, ou se pode ser adquirido por meio da educação; mais especificamente, ao seguir certas regras e ao emular um modelo. Sobre essas vertentes, Paoliello explica:

O gosto adquirido diz respeito ao refinamento do lado racional, que resulta no bom gosto - considerado fundamental pelos teóricos e músicos setecentistas. Aspecto descrito como algo cultivado, aperfeiçoado por meio de exercício e aprendido através da imitação de modelos. Nos escritos, encontramos também referência ao gosto natural, que seria o gosto e o senso de harmonia e beleza implantados no ser pela natureza (2011, p. 25).

Para preceptistas como Montesquieu, ambos os gostos estão presentes na alma humana ao dizer que "o gosto adquirido afeta, muda, aumenta e diminui o gosto natural, tanto quanto o gosto natural afeta, muda, aumenta e diminui o gosto adquirido" (MONTESQUIEU, 2009 [1753], p. 16, trad.T. Coelho $)^{14}$. No entanto, o autor se limitará, em seu ensaio, a descrever e estudar o gosto adquirido, uma vez que, no que concerne à formação do gosto em geral, os preceitos e as regras dizem respeito apenas a essa faceta do gosto.

Em relação ao gosto natural, ou seja, um senso de beleza e de harmonia inerente ao ser, teóricos como Ussherem Clio: or, Adiscourseontaste, explicam-no por analogia:

Um concerto que tem todas as suas partes bem compostas e bem executadas [...] agrada universalmente, mas, se surge uma dissonância [...], desagradará até aqueles absolutamente ignorantes em música. Eles não sabem o que os incomoda, mas sentem algo dissonante em seus ouvidos; e isto procede através do gosto e do senso de harmonia implantado neles pela natureza. Da mesma maneira, a pintura encanta e transporta o espectador que não tem noçóes sobre pintura. Pergunte a ele o que o agrada e ele não 
saberá especificar a razão ${ }^{15}$ (USSHER, 1772 [1769], p. 3-4 apud PAOLIELLO, 2011, p. 27, trad. N. Paoliello).

No entanto, a despeito de diversos estudos em que o foco principal é a característica natural do gosto, são muitos os tratadistas que defendem a sua vertente adquirida, entre eles o já mencionado Charles Batteux, além dos tratadistas musicais Joseph Joachim Quantz (1697-1773), Leopold Mozart (1719-1787), e, finalmente, Francesco Geminiani. Para esses autores, a prática de diversas regras, assim como a imitação, ou melhor, a emulação de um modelo são caminhos seguros para o refinamento e o aperfeiçoamento de habilidades naturais do ser.

Montesquieu dedica um capítulo - intitulado "Das regras” - a essa especulação, afirmando que todas as obras de arte têm regras gerais, que são guias a nunca perder de vista, e argumenta que o gosto deve ser construído no ser humano desde a juventude, pois, se a alma é exercida pelos sentimentos, somente o gosto poderia conduzi-la. Batteux explica que é da natureza do homem ter algum talento: "como uma mãe benfazeja ela [a natureza] nunca produz um homem sem dotá-lo de alguma qualidade útil que lhe sirva de recomendação junto aos outros homens" (BATTEUX, 2009 [1746], p. 82, trad. N. Maruyama $)^{16}$. No entanto, é o gosto que nutre esse talento, e, sem ele, este último não poderá ser aflorado, de modo que essa conduta contraria as intençóes da natureza.

Na música, a construção do gosto segundo as preceptivas dedicadas a essa arte é abordada de maneira mais direta. Leopold Mozart, por exemplo, expóe que "tudo o que pertence a uma performance de bom gosto pode, apenas, ser aprendido pelo julgamento do som e pela longa experiência” (MOZART, 1985 [1756], p. 216; trad. nossa) ${ }^{17}$. Geminiani, de outra forma, decide instruir os aspirantes à execução de bom gosto por intermédio de regras, como se pode observar no título de seu primeiro tratado: Regras para tocar com verdadeiro gosto. Assim, vê-se que o título não foi escolhido por acaso: na realidade, está em consonância com as correntes filosóficas da época. O refinamento, para Geminiani, ocorreria por meio do treino e da
15. "A concert, says he, that has all its parts well composed and well executed, both as to instruments and voices, pleases universally; but if any discord arises, any ill tone of voice be intermixed, it shall displease even those who are absolutely ignorant of music. They know not what it is that offends them, but they find somewhat grating in it to their ears; and this proceeds from the taste and sense of harmony implanted in them by nature. In like manner a fine picture charms and transports a spectator who has no idea of painting. Ask him what pleases him, and why it pleases him, and he cannot easily give an account, or specify the real reason $[\ldots]$."

16. "En mere bienfaisante, elle ne produitaucun homme, sans le doter de quelquequalité utile, qui luifert de recommendation auprès des autres hommes".

17 "Whatever belongs to tasteful performance of a piece; which can only be learnt from sound judgement and long experience" (trad. do alemão E. Knocker.). 
18. "What is commonly call'd good Taste in singing and playing, has been thought for some Years past to destroy the true Melody, and the Intention of their Composers. It is supposed by many that a real good Taste cannot possibly be acquired by any rules of Art; it being a peculiar Gift of Nature, indulged only to those who have naturally a good Ear: And as most flatter themselves to have this Perfection, hence it happens that he who sings or plays, thinks of nothing so much as to make continually some favourite Passages or Graces, believing that by this Means he shall be thought to be a good Performer, not perceiving that playing in good Taste doth not consist of frequent Passages, but in expressing with Strength and Delicacy the Intention of the Composer. This Expression is what every one should endeavour to acquire, and it may be easily obtained by any Person, who is not too fond of his own Opinion, and doth not obstinately resist the Force of true Evidence."

19. "Those who play on the Violoncello will acquire a good Taste, by practising the upper Part of these Compositions; by endeavouring to execute with Exactness whatever they find there written, and at the same Time being very careful to stop in Tune, for without this particular, all they can do will be to no Purpose. They must also take Care to draw a long Bow, otherwise the Sound will not come out of the Instrument. prática. O volume a ser publicado no ano seguinte, isto é, em 1749, portanto, é a continuação desses ensinamentos. Sobre o gosto adquirido, o autor escreve:

O que é comumente denominado bom gosto no cantar e no tocar foi considerado, por alguns anos no passado, como algo que destrói a verdadeira melodia e a intenção de seus compositores. Muitos supóem que não é possível adquirir o verdadeiro bom gosto por meio de quaisquer regras da arte, pois trata-se de um dom particular da natureza, concedido apenas àqueles que têm naturalmente um bom ouvido. Como a maioria se exibe por possuir essa perfeição, tem-se, por consequência, que aquele que canta ou que toca pensa apenas em fazer continuamente suas diminuições e seus ornamentos favoritos, acreditando que, por isso, será reconhecido como um bom intérprete, não percebendo que tocar com bom gosto náo consiste em frequentes ornamentaçóes, mas em expressar com força e elegância a intenção do compositor. Essa expressáo é o que todos devem se esmerar para adquirir, e pode ser facilmente obtida por qualquer pessoa que náo seja afeiçoada a sua própria opiniáo e que náo resista obstinadamente à força da verdadeira evidência (GEMINIANI, 1749 , pref.; trad. e grifo nossos) ${ }^{18}$.

De outro modo, em uma passagem do prefácio de suas Regras para tocar com verdadeiro gosto, explica:

Aqueles que tocam violoncelo adquirirão o bom gosto ao praticar a linha superior destas composiçóes, empenhando-se em executar com exatidáo tudo o que encontrarem escrito nelas. Ao mesmo tempo, devem ser muito cuidadosos com a afinaçáo, visto que, sem esta particularidade, tudo o que forem capazes de fazer náo terá nenhum proveito. Eles devem ter cuidado também para traçar um arco longo; caso contrário, o som náo sairá do instrumento (GEMINIANI, 1748, pref.; trad. e grifo nossos) ${ }^{19}$.

No entanto, assim como Montesquieu, Geminiani reconhece as potencialidades do gosto natural e menciona em seu texto: "[...] Não nego as capacidades marcantes de um bom ouvido, cuja força presenciei em diversas instâncias. Aponto, apenas, que certas regras da arte são necessárias a um engenho 
mediano, que podem melhorar e aperfeiçoar um que seja, por si, bom” (GEMINIANI, 1749, pref.; trad. nossa) ${ }^{20}$.

Com isso, podemos confirmar que Geminiani não apenas aceita, mas também recomenda o gosto adquirido. Portanto,uma vez que a ideia de construção e refinamento do gosto por meio de diversas regras era algo corrente no século XVIII, deve-se ressaltar que os preceptistas estavam cientes de que elas deveriam ser utilizadas de modo judicioso, ou seja, conforme ao decoro. As regras eram, pois, um guia, e suas aplicaçôes diligentes dependiam do bom gosto do artífice para que fossem feitas as exceçóes necessárias, pois o bom gosto é um amor habitual à ordem (BATTEUX, 2009 [1746], p. 79). Sobre isso, Montesquieu explica:

Todas as obras de arte têm regras gerais, que são guias a nunca perder de vista. Mas assim como as leis são sempre justas em seu caráter geral, porém são quase sempre injustas em sua aplicação, também as regras, sempre verdadeiras em teoria, podem revelar-se falsas na hipótese real. Os pintores e escultores estabeleceram as proporçôes que o corpo humano deve ter e tomaram por medida comum o comprimento do rosto. Mas a todo instante eles têm de violar essas proporçóes em virtude das diferentes atitudes nas quais têm de mostrar os corpos humanos; por exemplo, um braço estendido é bem mais comprido do que outro recolhido(2009 [1753], p. 69, trad. T. Coelho) ${ }^{21}$.

A abordagem de Geminiani está, portanto, de acordo com os demais tratadistas do século XVIII, sobretudo musicais. Leopold Mozart, por exemplo, é bastante rígido arespeito do emprego diligente da ornamentação e condena o uso abusivo de embelezamentos desprovidos de significado:

Todas essas decoraçóes são empregadas, porém, apenas ao tocar um solo e, portanto, com muita moderaçáo, no momento certo, e somente para [proporcionar] variedade em passagens similares e frequentemente repetidas. Além disso, observemos bem as direçóes do compositor, pois é na aplicação de tais ornamentos que a ignorância de alguém é mais prontamente revelada. Em particular, no entanto, protegemo-nos contra todos os embelezamentos improvisados quando muitos [músicos] tocam uma [mesma]
20. I would not however have it supposed that I deny the powerful Effects of a good Ear; as I have found in several Instances how great its Force is; I only assert that certain Rules of Art are necessary for a moderate Genius, and may improve and perfect a good one."

21. "Touslesouvrages de l'artontdesrèglesgénérales, quisontdesguidesqu'il ne faut jamais perdre de vue. Mais commelesloissonttoujours justes dansleurêtregéné- ral, mais presquetoujoursinjustesdansl'application ; de mêmelesrègles, toujoursvraiesdanslathéorie, peuventdevenirfaussesdansl'hypothèse. Les peintres et les sculpteursontétabli les proportions qu'ilfaut donner au corps humain, et ontpris pour mesure commune la longueur de la face ;maisilfautqu'ils violent à chaque instant 2 les proportions, à cause des différentes attitudes dans 
22. "All these decorations are used, however, only when playing a solo, and then very sparingly, at the right time, and only for variety in often-repeated and similar passages. And look well at the directions of the composer; for in the application of such ornaments is one's ignorance soonest betrayed. But in particular, guard against all improvised embellishments when several play from one part. What confusion would ensue, if every player should befrill the notes according to his own fancy? And finally one would not understand then aught of the melody, by reason of the various clumsily inserted and horrible 'beauties'? I know how it frightens one, when one hears the most melodious pieces distorted so pitifully by means of unnecessary ornamentations." (trad. do original alemãoE. Knocker)

23. "Everything depends on good execution. This saying is confirmed by daily experience. Many a wouldbe composer is thrilled with delight and plumes himself anew when he hears his musical Galimatias played by good performers who know how to produce the effect (of which he himself never dreamed) in the right place; and how to vary the character (which never occured to him) as much as it is humanly possible to do so [...]. The good performance of a composition according to modern taste is not easy as many imagine, who believe themselves to be doing well if they embellish and befrill parte. Qual confusão se sucederia se cada instrumentista enfeitasse as notas de acordo com sua própria fantasia? E, finalmente, náo se entenderia de modo algum a melodia devido à inserção desajeitada das 'belezas? Eu sei como isto amedronta [o ouvinte]: quando se ouve as peças mais melodiosas lamentavelmente distorcidas por conta de ornamentaçôes desnecessárias (MOZART, 1985 [1756], p. 214 ; trad. nossa) $)^{22}$.

Em sequência, conclui:

Tudo depende da boa execução. Esta afirmação pode ser confirmada pela experiência diária. Muitos aspirantes a compositor são excitados com deleite e vangloriam-se copiosamente quando ouvem suas "escalinhas" executadas por bons intérpretes que sabem como produzir o efeito (do qual [esses compositores] jamais sonharam) no lugar correto, além de como variar o caráter (do qual [também] nunca ocorrera a eles) o mais humanamente possível. [...] A boa interpretação de uma composição, de acordo com o gosto atual, não é tão simples como muitos imaginam ao acreditarem que estão fazendo bem ao embelezar e enfeitar a peça futilmente com suas ideias, e, também, por não terem a sensibilidade de qual afeto deverá ser expresso na peça (MOZART, 1985 [1756], p. 215 ; trad. nossa) $)^{23}$.

Carl Philipp Emanuel Bach também condena os que executam notas rápidas desprovidas de sentido. Ele diz:

Pode-se muito bem ter os dedos mais hábeis, saber fazer trinados simples e duplos, entender bem o dedilhado, tocar à primeira vista qualquer que seja o número de claves que se possam encontrar no decorrer da peça, transpor sem esforço e de improviso, alcançar intervalos de décima, ou mesmo duodécima, executar tiradas e cruzamentos de todo tipo, e muitas outras coisas ainda, e apesar de tudo isso náo se ter no teclado um toque claro, agradável e comovente (BACH, 2009 [1762], p. 133, trad. F. Cazarini) ${ }^{24}$.

Para que o discurso musical seja eloquente, o autor enfatiza, então, que a boa execução consiste em se "fazer ouvir com facilidade todas as notas e seus ornamentos na hora certa, com a força conveniente e um toque que corresponde ao ver- 
dadeiro caráter da peça, [pois] é aí que nascem o redondo, o puro e o contínuo no toque, que se torna claro e expressivo" (BACH, 2009[1762], p. 134, trad. F. Cazarini $)^{25}$. De maneira muito clara, ele conclui que se deve "tocar com a alma, e não como um pássaro bem treinado” (BACH, 2009 [1762], p. 135 , trad. F. Cazarini) ${ }^{26}$. Já Geminiani, de modo mais exigente, afirma, sobre o continuísta, que "aquele que não tem outras qualidades além de tocar as notas no tempo e empregar as figuras tão bem quanto possível não passa de um acompanhador desventurado" (GEMINIANI, 1748, pref.; trad. nossa) ${ }^{27}$. Assim, a boa execução depende do bom entendimento da obra como um todo e do emprego correto dos elementos musicais, sobretudo a ornamentação, veículo essencial para mover a audiência.

Além desses requisitos, a execução de bom gosto, ou seja, aquela que, dentre outras coisas, afeta o ouvinte, depende, segundo os tratadistas musicais do século XVIII, de outro elemento de suma importância: que o próprio intérprete esteja afetado. Recordemo-nos de que, na retórica clássica, o mesmo deve ser almejado pelo orador. Quintiliano diz:

De fato, o essencial, segundo em verdade penso, acerca de provocar as emoçôes, está em que nos comovamos a nós mesmos. Realmente, por vezes seria até ridícula a imitação de lamentaçóes, de raiva e de indignação, se acomodarmos a ela apenas as palavras e a fisionomia, mas não o espírito. Pois, que outra coisa seria o motivo pelo qual alguns, certamente deplorando recente sofrimento, deem a impressão de se expressarem com eloquência e, de vez em quando, também a raiva torne eloquentes os incultos, senão que há neles uma força inata da mente e a própria autenticidade de costumes? Por isso, naquelas emoçóes que queremos sejam verossímeis, nós mesmos devemos nos adequar aos que na realidade são por elas afetados; e que o discurso avance com aquela disposição de espírito que gostaríamos fosse a do juiz. Porventura, afligir-se-á aquele que me ouvir falando sobre isso sem manifestação de dor? Encher-se-á de raiva se o mesmo que tenta provocá-la e até a exige não mostra algo semelhante? Provocarão lágrimas os olhos enxutos do advogado? Tais resultados não podem dar-se. Nada incendeia a não ser o fogo, nem molhando algo a náo ser com algum líquido, nem alguma coisa dá a outra um brilho que ela mesma não tenha. Portanto, primeiramente tentemos que para nós tenha força aquilo que que- a piece right foolishly out of their own heads, and who have no sensitiveness whatever for the affect which is to be expressed in the piece" (trad. do original alemão E. Knocker)..

24. "Man kan die fertigften

Finger, einfache und doppelteTrillerhaben, die Applicaturverftehen, vomBlattetreffen, es nfovieleSchluffelimLaufe des esvorkommenalsfiewollen, allesohnevieleMüheaus dem Stegereiftransponiren, Decimen, ja

Duodecimengreifen, Läufer und Kreutzfprünge von erleyArtenmachenkönnen, und was dergleichenmehrift; ennochnichteindeutlicher, ein gefälliger,einrührenderClavie riftefeyn."

25. "Der guteVortragiftalfof ofortdaranzuerkennen, wenn man alleNotennebft den ih nenzugemeffenengutenM anierenzurechter Zeit in ihrergehörigenStärckedurcheinennach dem wahrenJnhalte des StücksabgewognenDruckmiteinerLeichtigkeithörenläßt. Hierausentftehet das Runde, Reine und Flieffende in der Spielart, und wird man dadurchdeutlich und ausdrückend.”

26. "Aus der Seelemuß man fpielen, und nichtwieeinabgerichteter Vogel.”

27. "He who has no other Qualities than that of playing the Notes in Time, and placing the Figures, as well as he can, is but a wretched Accompanyer." 
28; "Summaenim, quantum ego quidemsentio, circamovendosadfectus in hoc posita est, ut moveamuripsi. Nam et luctus et irae et indignationisaliquandoetiamridiculafueritimitatio, si verba vultumque tantum, non etiamanimumaccommodarimus. Quid enimaliud est causae ut lugentesutique in recentidoloredisertissimequaedamexclamarevideantur, et ira nonnumquamindoctisquoqueeloquentiamfaciat, quam quod illis inest vis mentis et veritasipsamorum? Quare, in iisquae esse veri similia volemus, simusipsisimileseorumquiverepatiunturadfectibus, et a tali animo proficiscaturoratioqualemfacereiudicivolet. An illedolebit qui audiet, me, qui in hoc dicam, non dolente?Irascetur, si nihil ipse qui in iram concitat ei quod exigitsimilepatietur? Siccisagentisoculis lacrimas dabit? Fieri non potest: necincenditnisiignisnecmadescimusnisiumore 'nec res ulladatalteri colorem quem non ipsahabet.' Primum est igitur ut apud nosvaleanteaquaevalere apud iudicemvolumus, adficiamurqueantequamadficereconemur."

29. "Before beginning to play, the piece must be well looked at and considered. The character, tempo, and kind of moviment demanded by the piece must be sought out, and carefully observed wheter a passage occurs not therein which often at first sight seems of little importance, but on account of its special style of execution and expression is not quite easy to play at sight. Finally, in practising remos que também o juiz assim a considere e nos emocionemos antes de emocionar a outrem(VI II, 26-28, trad. B. Bassetto) ${ }^{28}$.

Neste sentido, a tratadística musical mais importante do século XVIII também recomendará que o intérprete, assim como o orador, esteja afetado a si próprio para que sua performance possa efetivamente atingir o ouvinte. Em primeiro lugar, o afeto correto da peça deve ser identificado. Embora óbvia, esta instrução é recorrente nos tratados de Leopold Mozart, Carl Philipp Emanuel Bach e Johann Joachim Quantz. Do contrário, seria indecoroso - de mau gosto - expressar o afeto inadequado. Em seguida, o instrumentista deveria ser capaz de transmiti-lojudiciosamente ao público. Leopold Mozart afirma:

Antes de começarmos a tocar, a peça deve ser bem observada e considerada. O caráter, o tempo e o tipo de movimento demandados pela peça devem ser investigados, bem como [deve-se] observar cuidadosamente se alguma passagem nela contida que, à primeira vista, pode parecer de pouca importância é, se tratada com estilo especial de execução e expressão, difícil de executar. Finalmente, ao praticar, todo o cuidado deve ser tomado para encontrar e para tornar o afeto que o compositor desejou que tivesse sido trazido. Assim, como a tristeza, em geral, alterna-se com a alegria, cada uma deve ser cuidadosamente retratada de acordo com o seu tipo. Em uma única palavra, tudo deve ser tocado de modo que o intérprete seja [também] movido [pelos afetos] (MOZART, 1985 [1756], p.218; trad. e grifo nossos) ${ }^{29}$.

Semelhantemente, C. P. E. Bach instrui seus leitores a reconhecer o afeto adequado em determinada obra musical, pois deve-se tocar cada peça de acordo com seu verdadeiro caráter e com o afeto que lhe convém (BACH, 2009[1762], p. 138), e conclui que o mais importante de tudo é que o intérprete deva estar emocionado antes de querer emocionar sua plateia:

Um músico não provoca emoçóes se não estiver emocionado: é indispensável que ele se coloque em todos os afetos que quer evocar nos seus ouvintes e dê a entender seus sentimentos, para poder compartilhá-los melhor. Em trechos doces e tristes, ele deve ficar doce e triste. Deve-se ver e ouvir isso. Deve-se tomar cuidado aqui para não retardar e arrastar demais. Facilmente se 
incorre nesse erro, através de muito afeto e melancolia. $\mathrm{O}$ mesmo ocorre com trechos animados, alegres, ou de outros tipos, em que o músico deve se colocar nesses afetos. Logo que ele exprimiu uma ideia, surge outra, e assim, sem cessar, ele deve transformar suas paixóes. Tal tarefa ele deve desempenhar sobretudo nas peças expressivas, compostas por ele ou por outros. Nesse último caso ele terá que experimentar as mesmas paixóes que o compositor da peça teve ao compô-la (BACH, 2009 [1762], p. 137, trad. F Cazarini) ${ }^{30}$.

Assim, se é disso que também dependem a construção e o emprego do bom gosto, as obras de Francesco Geminiani revelam-se totalmente alinhadas com os tratadistas mencionados. O autor, no tratado de 1749 , discute sobre as potencialidades da música sobre seus ouvintes:

Homens de entendimento limitado e de meias ideias perguntarâo talvez se é possível conferir sentido e expressão à madeira e ao arame; ou dar a eles o poder de despertar e de acalmar as paixóes dos seres racionais. No entanto, toda vez que ouço tal questionamento, seja por desinformaçáo ou com o intuito de ridicularizar, não tenho nenhuma dificuldade em responder de forma afirmativa e sem investigar a causa muito profundamente, pois penso que seja suficiente apelar para o efeito. Mesmo no discurso comum, uma diferença do tom [de voz] dá à mesma palavra sentidos diferentes. Assim, no que diz respeito à interpretação musical, a experiência tem mostrado que a imaginação do ouvinte está, em geral, à disposição do mestre em tal proporçấo que, com a ajuda de variaçóes, andamentos, intervalos e melodias com harmonia, pode praticamente estampar a impressão que lhe agrada na mente [dos ouvintes] (GEMINIANI, 1749, p. 3-4, trad. nossa) ${ }^{31}$.

Desse modo, o autor demonstra acreditar que a execução musical depende de aspectos que caminham para muito além das instruçóes contidas na partitura, embora estas sejam importantes para uma boa compreensão da obra. Geminiani afirma que a música é capaz de comandar as paixóes de seus ouvintes e tem como prova disso o efeito que uma interpretação judiciosa e de bom gosto tem na mente de seu público: para ele, com o auxílio das ferramentas musicais à sua disposição, tanto o intérprete quanto o compositor poderão transmitir a expressão que desejarem. Além disso, exercendo uma every care must be taken to find and to render the affect which the composer wished to have brought out; and as sadness often alternates with joy, each must be carefully depicted according to its kind. In a word, all must be so played that the player himself be moved thereby." (trad. do original alemão E. Knocker).

30. "JndemeinMuficku snichtandersrührenkan, erfeydannfelbftgerührt; ußernothwendigfichfelbft in alleAffectenfetzenkönnen, welcheer bey feinenZuhörernerregen will; ergiebtihnenfeineEmp findungenzuverftehen und bewegtfiefolchergeftalt am beftenzurMit-Empfindung. Bey matten und traurigenStellenwirder matt und traurig. Manfieht und hört es ihm an. Diefesgefchichtebenfalls bey heftigen, luftigen, und andernArten von Gedancken, wo erfichalsdenn in diefeAffectenfetzet. Kaum, daßereinenftillt, foerregtereinenandern, fo lglichwechfelterbeftändig mitLeidenfchaften ab. Di efeSchuldigkeitbeobachte terüberhaupt bey Stücken, heausdrückendgefetztfind, fiemögen von ihmfelbftoder von jemandenandersherrühren; imletzternFallemuße rdiefelbeLeidenfchaften bey fichempfinden, welche der Urheber des fremdenStücks bey deffenVerfertigunghatte."

31. "Men of purblind Understandings, and half Ideas may perhaps ask, is it possible to give Meaning and Expression to Wood and Wire; or to bestow upon them the Power 
of raising and soothing the Passions of rational Beings? But whenever I hear such a Question put, wheter for the Sake of Information, or to convey Ridicule, I shall mak no Difficulty to answer in the affirmative, and without searching over-deeply into the Cause, shall think it sufficient to appeal to the Effect. Even in common Speech a Difference of Tone gives the same Word a different Meaning. And with regard to musical Performances, Experience has shewn that the Imagination of the Hearer is in general so much at the Disposal of the Master that by the Help of Variations, Movements, Intervals and Modulation he may almost stamp what Impression on the Mind he pleases."

32. "These extraordinary Emotions are indeed most easily excited when accompany'd with Words; and I would besides advise, as well the Composer as the Performer, who is ambitious to inspire his Audience to be first inspired himself, which he cannot fail to be if he chuses a Work of Genius, if he makes himself thoroughly acquainted with all its Beauties; and if while his Imagination is warm and glowing he pours the same exalted Spirit into his own Performance."

33. "The Road to Emulation is both open and wide; the most effectual Method to triumph over an Author is to excel him; and he manifests his Affection to a Science most who contributes most to its Advancement."

34. "Utileigiturhaberequosimitari primum, moxvincerevelis: ita emulação da retórica clássica, o autor também conclui que o intérprete deve estar afetado pelas emoçôes que ele deseja transmitir à sua audiência:

Essas emoçôes extraordinárias são, de fato, mais facilmente excitadas se acompanhadas de palavras. Eu aconselharia, ainda, tanto ao compositor como ao intérprete que ambiciona inspirar sua plateia, que inspirasse primeiramente a si mesmo, tarefa em que não falhará se escolher uma obra engenhosa, tornando-se totalmente familiarizado com todas as suas belezas, e se, enquanto sua imaginaçấo estiver vívida e flamejante, ele se embeber do mesmo espírito exaltado em sua própria interpretação (GEMINIANI, 1749, p. 3; trad. nossa) ${ }^{32}$.

Vale lembrar que o termo emulação faz parte do léxico utilizado pelo próprio Geminiani. Esse conceito, além de ser bastante difundido nas obras filosóficas acerca da construção do gosto, é, para o autor, um caminho seguro para o correto refinamento do verdadeiro gosto em todos os ramos do conhecimento, pois crê que "[...] o caminho para a emulação é aberto e amplo. $\mathrm{O}$ método mais eficaz para triunfar sobre um autor é superá-lo, e mais manifesta a sua afeição por uma ciência aquele que melhor contribui para o seu avanço" (GEMINIANI, 1749, p. 4; trad. nossa) ${ }^{33}$. Dessa maneira, o tratadista alinha-se com os preceitos de Quintiliano:

Portanto, é útil ter primeiramente a quem imitar, caso queiras depois superá-lo: assim, aos poucos, haverá esperança de chegar a pontos mais altos. A isso acrescento que os mestres não podem imaginar as mentes e os espíritos ao falar a apenas um presente, da mesma forma quando inspirados pela multidão de ouvintes(I II, 29, trad. B. Bassetto) ${ }^{34}$.

Desse modo, uma leitura cuidadosa e contextualizada de sua obra nos permite reconhecer que seus escritos se equiparam às demais preceptivas filosóficas e musicais referenciadas aqui. Além de estar envolvido nas questôes sobre Gosto, Geminiani demonstrou, também, conhecer a retórica, uma vez que seus tratados contêm instruçóes semelhantes às encontradas na obra de Quintiliano. Além disso, da maneira como expusemos anteriormente as ocasióes em que Geminiani relaciona um ornamento a um ou mais afetos em sua lista, o 
mesmo pode ser feito em relação às suas emulações retóricas presentes, sutil (sugerindo o conceito de variedade) ou explicitamente (comparando o discurso musical ao do orador), no mesmo fragmento:

(Quinto) Dotenuto: é necessário utilizá-lo frequentemente, pois se tivéssemos que realizar mordentes e trinados continuamente sem, às vezes, trazer prejuízo à sonoridade da nota pura, a melodia seria demasiadamente diversificada.

(Sexto) Dostaccato: expressa descanso, respiração ou mudança de palavra e, por essa razão, os cantores devem ser cuidadosos para respirar em um lugar em que o sentido [do texto] náo seja interrompido.

( $7^{\circ}$ e $8^{\circ}$ ) Do crescendo e do diminuendo: esses dois elementos podem ser realizados um após o outro. Produzem grande beleza e variedade na melodia e, quando empregados alternadamente, são próprios a qualquer expressão ou compasso.

( $9^{\circ}$ e $\left.10^{\circ}\right)$ Do piano e doforte: ambos são extremamente necessários para expressar a intenção da melodia e, como toda boa música deve ser composta imitando um discurso, esses dois ornamentos são designados a produzir os mesmos efeitos que um orador produz ao elevar e ao diminuir sua voz.

(Décimo primeiro) Da antecipação: a antecipação foi inventada com vistas a variar a melodia, sem alterar a sua intenção. Quando for realizada com um mordente ou um trinado e tiver um crescendo, produzirá um efeito maior, especialmente se observarmos que devemos usá-la quando a melodia ascende ou descende por grau conjunto ${ }^{35}$ (GEMINIANI, 1749, p.2-3; trad. nossa).

O nono e o décimo exemplos referenciados anteriormente são uma demonstração clara de quão ciente da retórica clássica Geminiani demonstrou estar. Ao comparar a execução musical com um discurso oral, frisando as elevaçóes e as diminuiçôes do tom da voz, o autor demonstra relacionar-se, mais uma vez, para com Instituição Oratória, de Quintiliano:

Examinemos agora em que o futuro orador tira proveito da música. A música tem dois ritmos nas vozes e no corpo, pois é necessário que ambos tenham regras próprias. $\mathrm{O}$ músico Aristóxeno divide o relativo à voz em [...] ritmo e [...] melodia, um dos quais diz respeito à cadência e o outro, ao canto e aos sons. Assim sendo, porventura tudo isso não é necessário ao orador? O Primeiro deles se relaciona com a gesticulação, o segundo com a colocação das palavras e o terceiro com as inflexóes da voz que, na paulatim et superiorumspeserit. His adiciopraeceptoresipsos non idem mentis ac spiritus in dicendo posse conciperesingulis tantum praesentibus quod illacelebritateaudientiuminstinctos."

35. "(Fifth) Of Holding a Note: It is necessary to use this often; for were we to make Beats and Shakes continually without sometimes suffering the pure Note to be heard, the Melody would be too much diversify'd. (Sixth,)

Of the Staccato: This

Expresses Rest, taking Breath, or changing a Word; and for this Reason Singers should be careful to take Breath in a Place where it may not interrupt the Sense. (7th and $8 t h$ ) Of Swelling and Falling the Sound: These two Elements may be used after each other; they produce great Beauty and Variety in the Melody, and employ'd alternately, they are proper for any Expression or Measure. (9th and 10th) Of Piano and Forte: They are both extremely necessary to express the Intention of the Melody; and as all good Musick should be composed in Imitation of a Discourse, these two Ornaments are designed to produce the same Effects that an Orator does by raising and falling his Voice. (Eleventh) Of Anticipation: Anticipation was invented, with a View to vary the Melody, without altering its Intention: When it is made with a Beat or a Shake, and swelling the Sound, it will have a great- 
<?> "Verum quid exeapropriepetatfuturusoratordisseramus. Numerosmusicedupliceshabet, in vocibus et in corpore: utriusqueenim rei aptusquidam modus desideratur. VocisrationemAristoxenusmusicusdividit in $\rho 0 \theta \mu o ́ v$ et $\mu \varepsilon \dot{\lambda} \lambda \mathrm{o}$, quorumalterummodulatione, alterumcanore ac sonisconstat. Num igitur non haecomniaoratorinecessaria? Quorumunum ad gestum, alterum ad conlocationemverborum, tertium ad flexusvocis, qui sunt in agendo quoqueplurimi, pertinet: nisi forte in carminibus tantum et in canticisexigiturstructuraquaedam et inoffensacopulatiovocum, in agendo supervacua est, aut non compositio et sonus in orationequoque varie pro rerum modo adhibetur sicut in musice. Namque et voce et modulationegrandiaelate, iucundadulciter, moderatalenitercanittotaque arte consentit cum eorumquaedicunturadfectibus. Atqui in orando quoque intentio vocis, remissio, flexuspertinet ad movendosaudientiumadfectus, aliaque et conlocationis et vocis, ut eodem utar verbo, modulationeconcitationemiudicis, alia misericordiampetimus, cum etiamorganis, quibus sermo exprimi non potest, adficianimos in diversum habitumsentiamus." prática, são também muitas: a não ser talvez que apenas nos poemas e nos cantos se exijam certa estrutura e uma adequada convergência das vozes, que na oratória são dispensáveis, ou que não se usem no discurso a disposição das palavras e as inflexões da voz de modo tão variado conforme o assunto, como na música. E assim, tanto pela voz como pela modulação, o músico celebra com nobreza os grandes feitos, com doçura os agradáveis e os mais modestos com suavidade - e com arte completa ajusta os sentimentos àquilo que se está dizendo. E assim também ao discursar, a intensidade, o abaixamento e as inflexóes da voz visam despertar os sentimentos dos ouvintes; e, por um lado, pela inflexáo da frase e da voz, para usar o mesmo termo, buscamos o desagrado do juiz e, por outro, sua compaixão. Isso acontece também com os instrumentos musicais, com os quais não se podem expressar palavras, que percebemos levarem os espíritos a sentimentos diversos(I, X, 2225 , trad. B. Bassetto) ${ }^{36}$.

\section{CONSIDERAÇÕES FINAIS}

O presente artigo teve, como objetivo principal, reconhecer as diversas emulaçóes de retóricas clássicas na obra tratadística do compositor Francesco Geminiani, notadamente nas Regras para tocar com verdadeiro gosto (c. 1748), no Tratado sobre o bom gosto na arte da música (1749) e na Arte de tocar violino (1751). Observamos que o autor, inserido no contexto cultural condizente ao do século XVIII, entendia a música como análoga ao discurso verbal, em que ambos são guiados pelas regras da retórica. A música, tal qual a oratória, é dedicada a mover o ouvinte. Nas palavras de Geminiani - que se relaciona fortemente com as de Cícero e de Quintiliano -, ela deve expressar sentimentos, atingir a imaginação, afetar a mente e comandar as paixóes.

Vimos que, para isto, Geminiani discorre sobre diversas maneiras de se utilizar o recurso da ornamentação. No entanto, este caminho para mover o ouvinte só poderia ser concretizado se realizado com bom gosto. Desse modo, notamos particularidades em seu texto que se conectam a obras de preceptistas filosóficos importantes como Ussher, Zedler, Batteux, Montesquieu e Hume. Quanto aos autores musicais que se articulam a Geminiani nessa tópica, destacam-se Quantz, C. P. E. Bach, e L. Mozart. Sua preferência pelo conceito de gosto adquirido, que já 
se evidencia no frontispício com a proposiçâo de diversas regras, se torna ainda mais patente no decorrer de seus prefácios, que, embora reconheça as potencialidades do gosto natural, defende que o dom natural não se sustenta sem o labor do treino e da prática. As aplicaçóes das regras, bem como da ornamentação, no entanto, devem ser realizadas diligentemente, pois, se empregadas mecanicamente, não moverão seu receptor e deturparão o sentido da obra. Nesse aspecto, além dos tratadistas já mencionados, Geminiani, ao descrever os catorze ornamentos de expressão e relacionar muitos deles com os efeitos esperados no ouvinte, bem como ao instruir que o intérprete se deixe afetar pela própria performance a fim de poder deleitar sua audiência e, também, ao comparar o discurso musical com o oral, alinhou-se à retórica clássica de Cícero e de Quintiliano. O autor se aproximou da retórica, semelhantemente, ao expor o conceito de variedade, nasRegras para tocar com verdadeiro gosto, assim como o de emulação, no Tratado sobre o bom gosto na arte da música.

Finalmente, pode-se concluir que a obra tratadística de Francesco Geminiani está alinhada às correntes de pensamento do século XVIII. Seja no âmbito da performance, em que se destacou ainda em vida como violinista virtuose, seja no âmbito da reflexão, em que dedicou as últimas décadas de sua produção, Geminiani resumiu, em seus textos, diversos debates recorrentes na literatura musical de seu tempo. Assim, a discussão sobre Gosto em seus tratados traz consigo ampla bagagem retórica, cujas emulaçôes foram exploradas, expostas e analisadas ao longo deste artigo

\section{REFERÊNCIAS BILIOGRÁFICAS:}

BACH, Carl Philipp Emmanuel. Ensaio sobre a maneira correta de tocar teclado/Versuchüber die wahreart das Clavierzuspielen]. Campinas [Berlin]: Editora da Unicamp [Georg Ludwig Winter], 2009 [1762]. Trad. F.Cazarini.

BATTEUX, Charles. As belas-artes reduzidas a um mesmo princípio [LesBeauxArtsréduits a unmêmeprincipe]. São Paulo [Paris]: Humanitas [Durand], 2009 [1746]. Trad. N.Maruyama. 
CICERO, MarcoTullius. De oratore. Cambridge, MA: Harvard University Press, 1942. (Loeb Classical Library).Trad. E. W. Suton, H. Rackham.

GEMINIANI, Francesco. Rules for playing in a true taste. London: peloautor, 1748.

. A treatise of good taste in the art of musick. London: peloautor, 1749. . The art of playing on the violin.London: pelo autor, 1751 .

HUME, David. Tratado da natureza humana: uma tentativa de introduzir o método experimental de raciocinio nos assuntos morais[A treatiseonhumannature: being na attempttointroducethe experimental methodofreasonininto moral subjects]. Sáo Paulo [London]: Editora da Unesp [John Noon], 2009 [1739-1740].Trad. D.Danowski.

LUCAS, Mônica. Emulação de retóricas clássicas em preceptivas da musicapoetica.In: Revista OPUS, v. 20, n. 1, 2014, p. 71-94.

MONTESQUIEU, Charles-Louis de Secondat. $O$ gosto[EssaisurleGoût].São Paulo [Paris]: Iluminuras, 2005 [1753]. Trad. T. Coelho.

MOZART, Leopold. A treatise on the fundamental principles of violin playing[VersucheinergründlichenViolinschu le]. Oxford [Augsburg]: Oxford Univeristy Press [Johann Jacob Lotter], 1985 [1756]. Trad. E. Knocker.

NEVES, Marcus Vinícius Sant'annaHeld. Francesco Geminiani (1687-1762): comentários e tradução da obra teórica completa. Dissertação (Mestrado em Musicologia): Escola de Comunicaçôes e Artes, Universidade de São Paulo, São Paulo, 2017. Disponível em: http://www. teses.usp.br/teses/disponiveis/27/27157/tde-27092017101128/pt-br.php. Acesso em 2018-01-30 
PAOLIELLO, Noara de Oliveira. Os concertouvertures de Georg Phillip Telemann: um estudo dos gostos reunidos segundo as preceptivas setecentistas de estilo e gosto. Dissertação (Mestrado em Música) - Escola de Comunicações e Artes, Universidade de São Paulo, São Paulo, 2011.

QUANTZ, Johann Joachim. On playing the flute [Versuch einer Anweisung die Flöte Traversiére zu spielen]. Boston [Berlin]: Northeastern University Press [Voss], 2001 [1752]. Trad. E. Reilly.

QUINTILIANO, MarcusFabius. Instituição oratória [InstitutioOratoria]. Campinas [Roma]: Editora da Unicamp, 2015 [c. 95]. v. 1-4. Trad. B. Bassetto.

RIPA, C. Iconology: or, moral emblems. London: Benjamin Motte, 1709.

USSHER, John. Clio: or, a discourse on taste. London: T. Davies, 1769. 